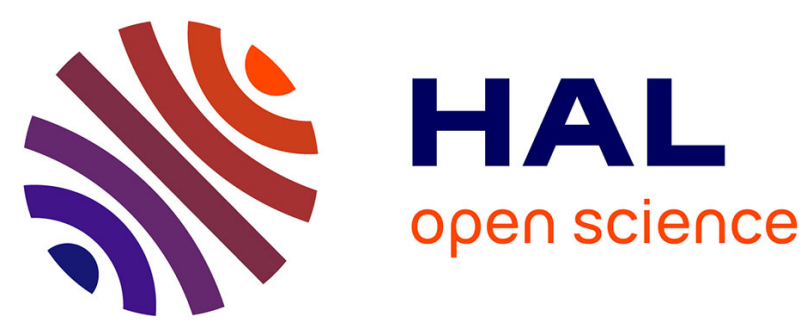

\title{
Non-Linear Analytical Model for a Multi-V-Shape IPM with Concentrated Winding
}

Paul Akiki, Maya Hage Hassan, Jean-Claude Vannier, Mohamed Bensetti, Dany Prieto, Benjamin Dagusé, Mike Mcclelland

\section{To cite this version:}

Paul Akiki, Maya Hage Hassan, Jean-Claude Vannier, Mohamed Bensetti, Dany Prieto, et al.. NonLinear Analytical Model for a Multi-V-Shape IPM with Concentrated Winding. IEEE Transactions on Industry Applications, 2018, 54 (3), pp.2165 - 2174. 10.1109/TIA.2018.2799175 . hal-01698194

\section{HAL Id: hal-01698194 \\ https://hal-centralesupelec.archives-ouvertes.fr/hal-01698194}

Submitted on 11 Mar 2020

HAL is a multi-disciplinary open access archive for the deposit and dissemination of scientific research documents, whether they are published or not. The documents may come from teaching and research institutions in France or abroad, or from public or private research centers.
L'archive ouverte pluridisciplinaire HAL, est destinée au dépôt et à la diffusion de documents scientifiques de niveau recherche, publiés ou non, émanant des établissements d'enseignement et de recherche français ou étrangers, des laboratoires publics ou privés. 


\title{
Non-Linear Analytical Model for a Multi-V-Shape IPM with Concentrated Winding
}

\author{
Paul Akiki, Maya Hage Hassan, Jean-Claude Vannier, Mohamed Bensetti, Dany Prieto, Mike McClelland
}

\begin{abstract}
This paper presents a non-linear analytical model of a multi-V-shape Interior Permanent Magnet (IPM) motor with non-overlapping concentrated winding. The model relies on Ampere's theorem and the flux conservation law in order to compute the flux density in the different parts of the motor. This article proposes a saturated analytical model of the stator and the rotor. The analytical model is used to calculate the average torque, the power factor and the voltage of the motor. It is 5 times faster than the 2D Finite Element Analysis (FEA). The results are compared to 2D FEA simulations and experimentally validated using a prototype motor.
\end{abstract}

Index Terms-Analytical model, Concentrated winding, Electrical machines, IPM motor, Multi-V-shape magnets.

\section{INTRODUCTION}

$\mathrm{R}$ ECENTLY, high performance motors have been the subject of many studies and research projects. Permanent magnet motors with rare earth materials are known for their suitability in high performance applications and have been widely used by industrials during the last decades [1], [2]. However, these magnets have reached high price, which increased the cost of the motor. In order to ensure competitiveness, varieties of motors, which do not use or with reduced rare-earth materials, have been extensively developed [3]. Non-rare-earth permanent magnets such as ferrite or alnico have attracted significant interest in recent designs. The low magnetic field created by these types of magnet leads to their use in a flux concentration configuration [4] or as an additional torque source in synchronous reluctance motors. This configuration is known as the Permanent Magnet Assisted Synchronous Reluctance Motor (PMASynRM) with distributed winding [5], [6].

In this paper, the studied structure is a multi-V-shape Interior Permanent Magnet (IPM) motor with non-overlapping concentrated winding. It has ferrite magnets in the rotor and short end-winding in the stator in order to reduce the Joule losses. The motor's design process usually starts by modelling the magnetic performance. The advances in computational tools made it possible to use Finite Element Analysis (FEA) to create a numerical simulation of the studied motor. FEA allows a detailed investigation of the motor behavior, with the disadvantage of generally long execution times [7]. In order to overcome this problem, analytical models based on creating a reluctance network or on solving Maxwell equations were

Paul Akiki, Maya Hage Hassan, Jean-Claude Vannier and Mohamed Bensetti are with GeePs | Group of electrical engineering-Paris, UMR CNRS 8507, CentraleSupélec, Univ.Paris-Sud, Université Paris-Saclay, Sorbonne Universités, UPMC Univ Paris 06, 3 \& 11 rue Joliot-Curie, Plateau de Moulon 91192 Gif-sur-Yvette, France.

(emails: paul.akiki@centralesupelec.fr,maya.hagehassan@centralesupelec.fr, jean-claude.vannier@centralesupelec.fr, mohamed.bensetti@centralesupelec.fr)

Dany Prieto and Mike McClelland are with Leroy Somer Motor, 16000 Angoulême, France. (e-mails: dany.prieto@mail.nidec.com, mike.mcclelland@mail.nidec.com) developed [8]-[10]. In this paper, an analytical model of a multi-V-shape IPM motor with non-overlapping concentrated winding is proposed. The model relies on two fundamental laws of electromagnetism: Ampere's theorem and flux conservation law [11].

The studied machine is an 18 slot/16 pole structure (Fig.1). It has open slots in order to facilitate the automatic insertion of the windings during the manufacturing process. The rotor presents an interior iron bridge and an exterior one. A fluxbarrier is mainly defined by 2 parameters: $\delta$ is the barrier's tilt angle and $k=\theta / \beta$ is the ratio of the barrier's opening angle with respect to the half pole angle $\beta$. This article proposes a saturated analytical model of the stator teeth and the stator yoke. It takes into account the leakage flux in the slots and the saturation in the rotor magnetic circuit [12]. The developed model is parameterized as a function of the slot number, the pole pair number and the magnet layer number.

(a)

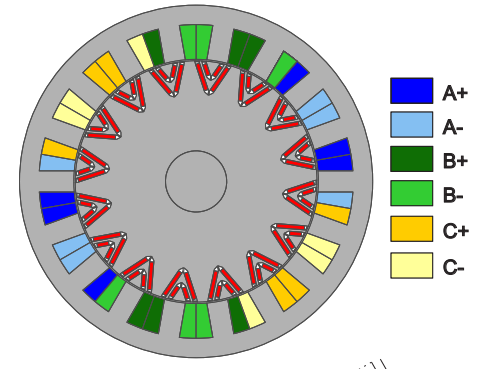

(b)

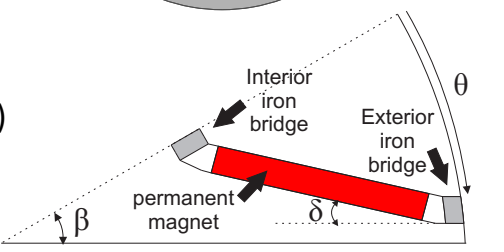

Fig.1 Studied motor structure (a) with the rotor's main geometrical parameters (b)

\section{ANALYTICAL MODEL}

The analytical model computes the flux density of the motor over one electrical period $\left(360^{\circ} \mathrm{elec}\right)$. Due to magnetic symmetry, half of the machine is modeled.

\section{A. Magnetomotive Force}

The machine is a three phase motor with a non-overlapping concentrated tooth winding. The magnetomotive force ( $\mathrm{mmf}$ ) is determined with respect to the winding pattern shown in Fig. 2 that covers one electrical period. The $m m f$ level of each tooth is given by the total current of the tooth coil as in (1). A linear variation of the $m m f$ in the slots is considered.

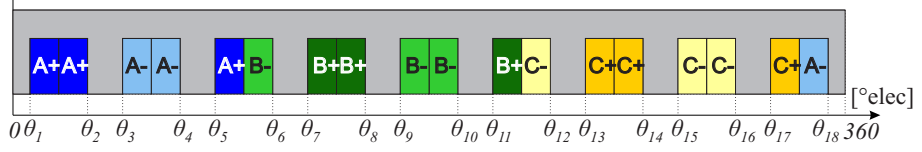

Fig. 2 Winding configuration for half of the motor $\left(360^{\circ} \mathrm{elec}\right)$ 


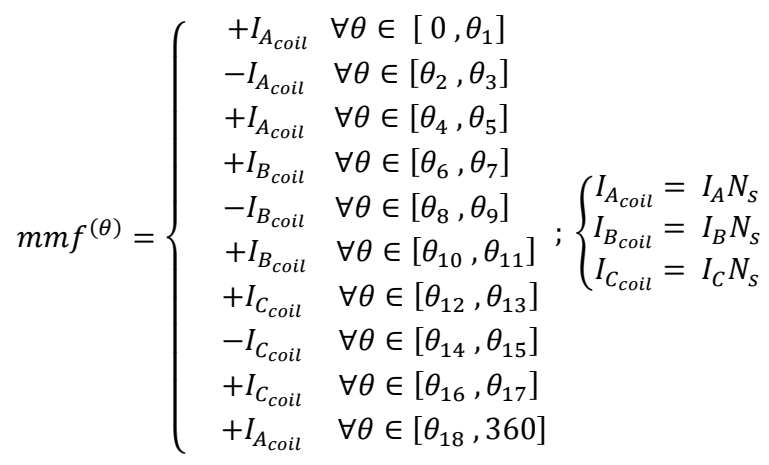

where $I_{A}, I_{B}, I_{C}$ are the currents in phases A, B, C respectively, and $N_{s}$ is the number of turns per coil.

\section{B. Stator Slots Additional Air-Gap}

Stator slotting influences the magnetic field by affecting the distribution of the flux density in the air-gap. It increases the reluctance of the flux path and reduces the air-gap flux density in front of a slot. Therefore, it is important to take it into account. A common method for modeling the stator slotting effect uses Carter's coefficient to smooth the stator geometry but assumes that the slot width is much smaller than its height [13]. In this paper, the additional air-gap length is calculated using the mean flux path under the slot opening [14]. Thus, idealized flux paths are shown in Fig.3. Assuming quartercircular flux lines with radii $R_{1}$ and $R_{2}$, the arc lengths $\Gamma_{l}$ and $\Gamma_{2}$ are given by:

$$
\left\{\begin{array}{c}
\Gamma_{1}(v)=\frac{\pi}{2} R_{s i} \sin (v) \\
\Gamma_{2}(v)=\frac{\pi}{2} R_{s i} \sin \left(\theta_{s l o t}-v\right)
\end{array}\right.
$$

where $\theta_{\text {slot }}$ is the slot opening angle, $R_{s i}$ is the internal radius of the stator and $v$ is the angle under the slot opening. The additional air-gap $e_{s}(v)$ is the equivalent length of the two parallel paths $\Gamma_{1}$ and $\Gamma_{2}$. The use of the first-order Taylor expansion leads to (3):

$$
e_{s}(v)=\left\{\begin{array}{cc}
\frac{\pi}{2 \theta_{\text {slot }}} R_{s i} v\left(\theta_{\text {slot }}-v\right) & \begin{array}{c}
\text { under slot } \\
\text { opening }
\end{array} \\
0 & \text { under stator } \\
\text { tooth }
\end{array}\right.
$$

The total air-gap length is given by:

$$
e_{t o t}(v)=e+e_{s}(v)
$$

where $e$ is the airgap length.

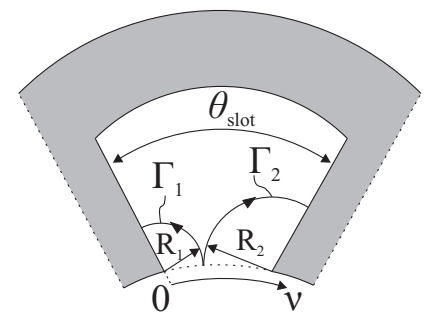

Fig.3 Idealized flux paths under stator slot

\section{Flux density of the stator}

The flux density of the stator is calculated in the teeth and the yoke. Assuming quarter-circular paths between the air-gap and the stator tooth (Fig.4), the tooth flux density is calculated using flux conservation law applied to the tooth pitch $\left(\theta_{\tau s t}\right)$ with a discretization of $1^{\circ} \mathrm{elec}$.

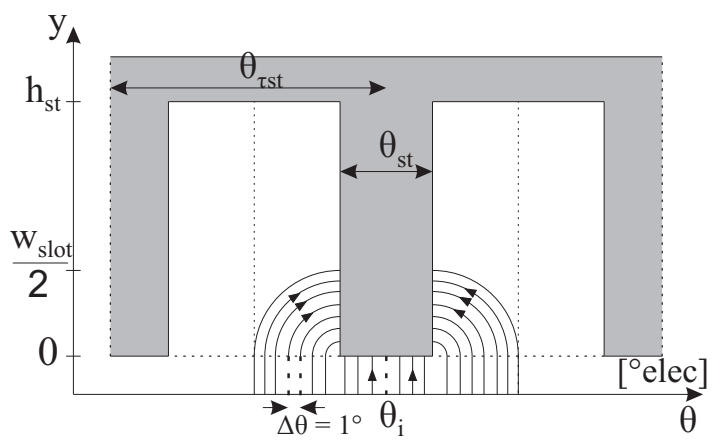

Fig.4 Flux lines between the airgap and the stator tooth

Equation (5) computes the stator tooth flux density $B_{s t}^{i}{ }_{a g}$ due to airagp flux density $B_{a g}(\theta)$ :

$$
\begin{aligned}
& \forall i \in\{1,9\} \quad ; \quad \forall n \in\left\{\frac{\theta_{s t}}{2}, \frac{\theta_{\tau s t}}{2}\right\} \\
& B_{s t_{a g_{n}}}^{i}=B_{s t_{a g_{n-1}}{ }^{i}}+\frac{R_{s i}}{w_{s t}}\left(\int_{\theta_{i}+n}^{\theta_{i}+(n+1)} B_{a g}(\theta) d \theta\right. \\
& \left.+\int_{\theta_{i}-(n+1)}^{\theta_{i}-n} B_{a g}(\theta) d \theta\right)
\end{aligned}
$$

where $w_{s t}$ is the stator tooth width, $\theta_{s t}$ is the tooth angular span and $\theta_{i}$ is the center angular position of the $\mathrm{i}^{\text {th }}$ tooth (Fig.4). The flux density for $\mathrm{n}=0$ is calculated using flux conservation law for the airgap flux under the stator tooth. Its expression is given by (6).

$$
B_{s t_{a g_{0}}}^{i}=\frac{R_{s i}}{w_{s t}} \int_{\theta_{i}-\frac{\theta_{s t}}{2}}^{\theta_{i}+\frac{\theta_{s t}}{2}} B_{a g}(\theta) d \theta
$$

Hence, we obtain $B_{s t_{a g}}^{i}(y)$ which is the airgap flux density for each tooth along the y-axis shown in Fig.4, for $0 \leq y \leq$ $\frac{w_{\text {slot }}}{2}$ where $w_{\text {slot }}$ is the slot width.

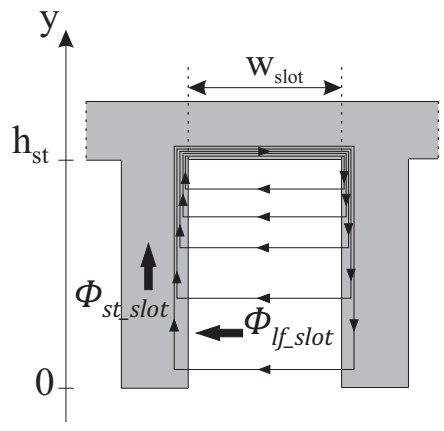

Fig.5 Tangential leakage flux in the stator slot

The tangential leakage flux that links two adjacent teeth is taken into account (Fig.5). The total current distribution in each slot is considered to be linear. Thus, Ampere's theorem is written on paths along the tooth height $h_{s t}$ as shown in Fig.5, and the flux conservation law is applied between the tangential leakage flux in stator slots $\phi_{\text {If slot }}(y)$ and the slot flux entering the tooth $\phi_{\text {st_slot }}(y)$.This yields (7) and (8).

$$
B_{l f_{s l o t}}(y)=\frac{B_{l f_{0}}}{C}\left(e^{A y}-e^{2 A h_{s t}} e^{-A y}\right)
$$




$$
\begin{aligned}
& B_{s_{s l o t}}(y)=\frac{1}{w_{s t}} \int_{0}^{y} B_{l f_{\text {slot }}}(u) d u \\
& =\frac{\mu_{0} I_{\text {slot }}}{w_{\text {slot }} w_{\text {st }} A C}\left[e^{A y}+e^{2 A h_{s t}}\left(e^{-A y}-1\right)-1\right]
\end{aligned}
$$

with $A=\sqrt{\frac{\mu_{0}}{w_{s l o t} w_{s t}}\left(\frac{1}{\mu_{s t} l}+\frac{1}{\mu_{d s r}}\right)} ; C=1-e^{2 A h_{s t}}$

where $\mu_{0}, \mu_{s t_{l}}, \mu_{s t_{r}}, I_{s l o t}$ are respectively, the vacuum permeability, the relative permeability of the left and the right stator tooth (surrounding the considered slot) and the total current of the considered slot. Therefore the total leakage flux density and the total flux density of a tooth along its height ( $y$ axis) are given by (9) and (10) respectively.

$$
\begin{aligned}
& B_{s t_{l f}}^{i}(y)=B_{s_{s l o t_{r}}}^{i}(y)-B_{s_{s_{s l o t}}}^{i}(y) \\
& B_{s t}^{i}(y)=B_{s t_{a g}}^{i}(y)+B_{s t_{l f}}^{i}(y)
\end{aligned}
$$

The subscripts $l$ and $r$ represent the left and the right sides of a tooth. The tooth flux density is considered constant along the tooth width $(\theta$-axis) so that the stator tooth flux density with respect to the electrical angle can be written:

$$
B_{s t}(\theta, y)=\left\{\begin{array}{cl}
B_{s t}^{i}(y) & \text { under the } i^{\text {th }} \text { tooth } \\
0 & \text { under the slots }
\end{array}\right.
$$

The stator yoke flux density is calculated by applying the flux conservation equation between the stator teeth and the yoke over a variation of $\Delta \theta=1^{\circ} \mathrm{elec}$. The stator yoke flux density with respect to the electrical angle $B_{s y}(\theta)$ is expressed by (12) for $0 \leq \theta \leq 360^{\circ}$ elec:

$$
B_{s y}(\theta+\Delta \theta) h_{s y}=B_{s y}(\theta) h_{s y}+B_{s t}(\theta, y) R_{y i} \Delta \theta
$$

where $h_{s y}$ is the yoke height and $R_{y i}$ is the yoke interior radius.

\section{Flux density of the rotor}

The flux density of the rotor has to be calculated for 8 poles, since we are dealing with the half of the machine. Fig. 6 shows one rotor pole with V-shape flux-barriers that are filled with magnets. The iron piece between two flux-barriers is called "flux-guide" (green area in Fig.6).

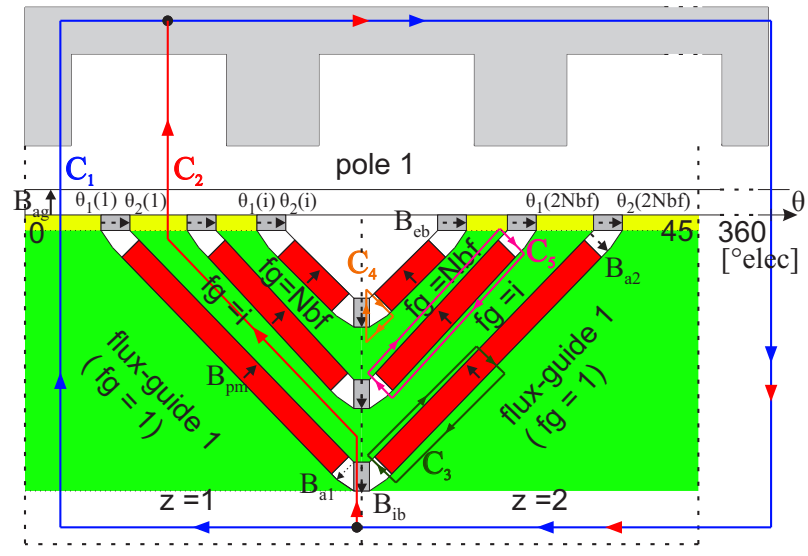

Fig.6 Motor general schematic and flux paths

Each rotor pole is divided into two zones $(z=1,2)$ and the rotor flux densities are modeled by the flux-guide mean path. At the flux-guide boundaries, the magnetic flux is assumed to be aligned in the same direction as the flux-guide mean path (Fig.7a). $N b f$ is the number of flux barriers. The flux is defined as $\phi^{(z, f g, p o l)}$ where $f g$ is the flux-guide number $(f g \in\{1, N b f\})$, and $\mathrm{pol}$ is the pole number ( $\mathrm{pol} \in\{1,8\}$ ). For the flux-guide between poles $(f g=1),(13)$ and (14) are written:

$$
\begin{aligned}
& \phi_{f g_{f}}^{(1,1, p o l)}=\phi_{a g}^{(1,1 p o l)}+\phi_{a g}^{(2,1, p o l-1)}+\phi_{e b_{0}}^{(1,1, p o l-1)} \\
& -\phi_{e b_{f}}^{(2,1, p o l-1)} \\
& \phi_{f g_{0}}^{(1,1, p o l)}=\phi_{f b}^{(1,1, p o l)}+\phi_{f b}^{(2,1, p o l-1)}+\phi_{f g_{f}}^{(1,1, p o l)}
\end{aligned}
$$

with $p o l=1$ if pol- $1=8$. For flux-guides between flux-barriers $(f g \in\{2, N b f\}),(15)$ and (16) are written with $z \in\{1,2\}$ :

$$
\begin{aligned}
& \phi_{f g_{f}}^{(z, f g, p o l)}=\phi_{a g}^{(z, f g, p o l)}-(2-z) \phi_{e b_{f}}^{(z, f g-1, p o l)} \\
& +(2-z) \phi_{e b_{0}}^{(z, f g, p o l)}+(z-1) \phi_{e b_{0}}^{(z, f g-1, p o l)} \\
& -(z-1) \phi_{e b_{f}}^{(z, f g, p o l)} \\
& \phi_{f g_{0}}^{(z, f g, p o l)}=\phi_{i b}^{(f g-1, p o l)}-\phi_{i b}^{(f g, p o l)}+\phi_{f b}^{(z, f g, p o l)} \\
& -\phi_{f b}^{(z, f g-1, p o l)}+\phi_{f g_{f}}^{(z, f g, p o l)}
\end{aligned}
$$

where $\phi_{f g_{f}}, \phi_{f g_{0}}$ are the boundary fluxes of the rotor fluxguides. $\phi_{e b_{f}}, \phi_{e b_{0}}$ are the boundary fluxes of the exterior iron bridges. $\phi_{i b}$ and $\phi_{a g}$ are the fluxes of the interior iron bridge and the airgap respectively. $\phi_{f b}$ is the flux crossing the fluxbarrier.

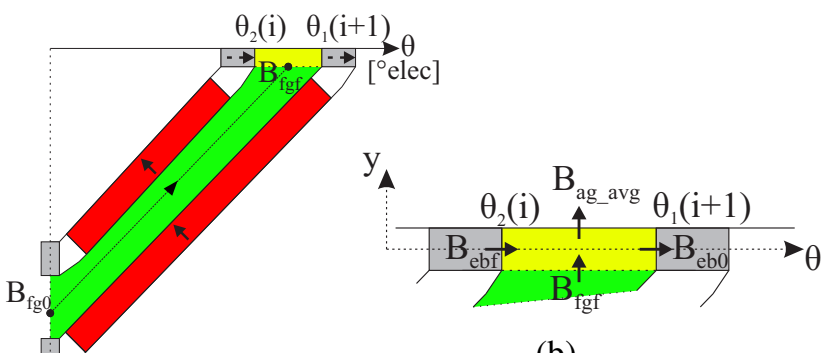

(a)

(b)

Fig.7 Flux density mean path in a rotor flux-guide (a). Local saturation near the exterior iron bridge $(b)$

The boundary flux densities are then given by (17) - (20)

$$
\begin{aligned}
& B_{f g_{f}}^{(1,1, p o l)}=\frac{\phi_{f g_{f}}^{(1,1, p o l)}}{2 w_{f g_{f}}(1)}=B_{f g_{f}}^{(2,1, p o l-1)} \\
& B_{f g_{0}}^{(1,1, p o l)}=\frac{\phi_{f g_{0}}^{(1,1, p o l)}}{2 w_{f g_{0}}(1)}=B_{f g_{0}}^{(2,1, p o l-1)} \\
& B_{f g_{f}}^{(z, f g, p o l)}=\frac{\phi_{f g_{f}}^{(z, f g, p o l)}}{w_{f g_{f}}(f g)} \\
& B_{f g_{0}}^{(z, f g, p o l)}=\frac{\phi_{f g_{0}}^{(z, f g, p o l)}}{w_{f g_{0}}(f g)}
\end{aligned}
$$

where $w_{f g_{f}}$ and $w_{f g_{0}}$ are the boundary widths of the fluxguides. A linear interpolation is used between the boundary flux densities in order to compute the interior flux densities of each flux-guide.

The iron bridges are generally saturated. Hence, the $m m f$ drop of the rotor flux-guide near the iron bridge is higher than other areas. To take into account this local saturation phenomenon, the area near the exterior iron bridges is 
modeled separately (Fig.7b). We assume a linear variation of the flux density between two bridges in the $\theta$-axis $\left(B_{x}(\theta)\right)$. The boundary flux density of the flux-guide $B_{f g f}$ and the average value of the airgap flux density $\boldsymbol{B}_{\text {agavg }}$ are used to calculate an average value of the flux-guide flux density in the $y$-axis:

$$
B_{y}=\frac{B_{a g_{a v g}}+B_{f g_{f}}}{2}
$$

Thus, for the electrical angle between $\theta_{2}(i)$ and $\theta_{l}(i+1)$ the flux-guide local saturation flux density is given by:

$$
B_{\text {local }_{\text {sat }}}(\theta)=\sqrt{B_{x}(\theta)^{2}+B_{y}^{2}}
$$

\section{E. Equations of the global system}

The motor general scheme is shown in Fig.6. The magnets are inserted in the $\mathrm{V}$-shape flux-barriers and are surrounded by air from both sides. The model considers the non-linearity of the ferromagnetic material. The electrical angular position $\theta$ is discretized from 0 to $360^{\circ}$ along the airgap. Ampere's theorem is written on five contours ( $\mathrm{C} 1$ to $\mathrm{C} 5$ ) and expressed by (23) to (27), respectively.

$$
\begin{aligned}
& H_{a g}^{(\theta)} e_{t o t}^{(\theta)}-H_{a g}^{(360)} e_{t o t}^{(360)}+A t_{s}^{(\theta)}-A t_{s}^{(360)}+A t_{r}^{(\theta)} \\
& -A t_{r}^{(360)}+m m f^{(\theta)}-m m f^{(360)}=0 \\
& H_{a g}^{(\theta)} e_{t o t}^{(\theta)}-H_{a g}^{(360)} e_{t o t}^{(360)}-\sum_{m=1}^{f g-1}\left(H_{i b}^{(m, p o l)} h_{i b}^{(m)}\right) \\
& +A t_{s}^{(\theta)}-A t_{s}^{(360)}+A t_{r}^{(\theta)}-A t_{r}^{(360)}+m m f^{(\theta)} \\
& -m m f^{(360)}=0 \\
& -H_{a 1}^{(z, n b, p o l)} w_{f b}^{(n b)}+(-1)^{p o l} H_{p m}^{(z, n b, p o l)} w_{p m}^{(n b)} \\
& +A t_{r}^{(z, n b, p o l)}=0 \\
& -H_{i b}^{(n b, p o l)} h_{i b}^{(n b)}+H_{a 1}^{(z, n b, p o l)} w_{f b}^{(n b)}=0 \\
& H_{a 2}^{(z, n b, p o l)} w_{f b}^{(n b)}-H_{a 1}^{(z, n b, p o l)} w_{f b}^{(n b)}+A t_{r}^{(z, n b, p o l)}=0
\end{aligned}
$$

where $n b$ is the number of the flux-barriers varying from 1 to $N b f . H, w$ and $h$ are respectively the magnetic field, the width and the height. The subscripts $p m, f b, i b, a l$ and $a 2$ represent the permanent magnet, the flux-barrier, the interior iron bridge and the air next to the magnet sides, respectively. $A t_{s}$ and $A t_{r}$ are the $m m f$ drop of the stator path (tooth + yoke) and the rotor path respectively. The above equations are completed with (28) that express the flux conservation law in the airgap.

$$
<B_{a g}>=0
$$

Equations (23) and (24) are not valid for the exterior iron bridge angular positions. The model above the exterior iron bridges is given in the next section (III-F).

The flux of the interior iron bridges is calculated by applying the flux conservation law in the central iron piece and between the flux-barriers for $p o l \in\{1,8\}$. Central iron piece:

$$
\begin{aligned}
& \sum_{z=1}^{2}\left\{(-1)^{p o l} \phi_{p m}^{(z, N b f, p o l)}+\phi_{f a 1}^{(z, N b f, p o l)}+\phi_{f a 2}^{(z, N b f, p o l)}\right\} \\
& +\phi_{a g}^{(1, N b f+1, p o l)}+\phi_{e b_{0}}^{(2, N b f, p o l)}-\phi_{e b_{f}}^{(1, N b f, p o l)}+\phi_{i b}^{(N b f)} \\
& =0
\end{aligned}
$$

Between two flux-barriers: $f g \in\{2, N b f\}$

$$
\begin{aligned}
& \sum_{z=1}^{2}\left\{\begin{array}{c}
(-1)^{p o l} \phi_{p m}^{(z, f g-1, p o l)}+\phi_{a 1}^{(z, f g-1, p o l)} \\
+\phi_{a 2}^{(z, f g-1, p o l)}+\phi_{a g}^{(z, f g, p o l)} \\
-(-1)^{p o l} \phi_{p m}^{(z, f g, p o l)}-\phi_{a 1}^{(z, f g, p o l)}-\phi_{a 2}^{(z, f g, p o l)}
\end{array}\right\} \\
& +\phi_{e b_{0}}^{(1, f g, p o l)}+\phi_{e b_{0}}^{(2, f g-1, p o l)}-\phi_{e b_{f}}^{(1, f g-1, p o l)} \\
& -\phi_{e b_{f}}^{(2, f g, p o l)}-\phi_{i b}^{(f g)}+\phi_{i b}^{(f g-1)}=0
\end{aligned}
$$

It is worth mentioning that (29) and (30) take into account the alternating magnetic orientation of the permanent magnet among poles.

\section{F. Flux density of the exterior iron bridge}

To complete the global system, the airgap flux density above the exterior iron bridge has to be computed. The flux conservation law (31) and Ampere's theorem (32) are used on the iron bridge as shown in Fig.8. The $m m f$ drop in the stator iron is included when applying Ampere's theorem.

$$
\begin{gathered}
B_{a g}\left(\theta_{i}\right)=\frac{h_{e b}}{R_{\text {rot }} \Delta \theta}\left(B_{e b}\left(\theta_{i}\right)-B_{e b}\left(\theta_{i+1}\right)\right) \\
1 \leq i \leq n+1 \\
R_{r o t} \int_{\theta_{1}}^{\theta_{i}} H_{e b}^{(\theta)} d \theta+\frac{B_{a g}^{\left(\theta_{i}\right)}}{\mu_{0}} e_{t o t}^{(\theta)}-\frac{B_{a g}^{\left(\theta_{1}\right)}}{\mu_{0}} e_{t o t}^{\left(\theta_{1}\right)}+A t_{s}^{\left(\theta_{i}\right)} \\
-A t_{s}^{\left(\theta_{1}\right)}+m m f^{(\theta)}-m m f^{\left(\theta_{1}\right)}=0 \\
2 \leq i \leq n+2
\end{gathered}
$$

where $(n+2)$ is the electrical angular span of the iron bridge. $R_{r o t}$ is the rotor radius and $h_{e b}$ is the height of the exterior iron bridge. Equation (32) is completed with the boundary value $B_{a g}\left(\theta_{1}\right)$. The airgap flux density above the iron bridge is then deduced by (31).

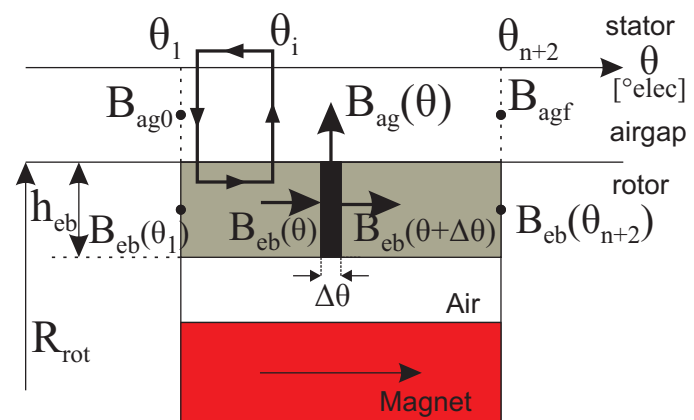

Fig.8 Exterior iron bridge: Ampere's theorem and flux conservation law

\section{G. Performance calculation}

The airgap flux density is used to calculate the stator phase flux linkages $\left(\phi_{a}, \phi_{b}, \phi_{c}\right)$. The slot leakage flux is added to obtain the total flux linked by the stator coils. Equation (33) gives the flux linkage of phase-A. For the other phases it is obtained by replacing the subscript $\mathrm{A}$ by $\mathrm{B}$ and $\mathrm{C}$.

$$
\phi_{a}=\frac{N_{c s}}{N_{c p}} N_{s} \sum_{k=1}^{m} R_{s i} L \int_{\theta_{A-k}}^{\theta_{A+k}} B_{a g}(\theta) d \theta+\phi_{s t_{l f}}
$$

where $\theta_{A+}$ and $\theta_{A-}$ are the center angular position of the coils A+ and A- (Fig.2), $m$ is the number of coils per phase per electrical period, $N_{c s}$ and $N_{c p}$ are the number of circuits in 
series and in parallel respectively, $L$ is the stack length The d$\mathrm{q}$ axis currents $\left(i_{d}, i_{q}\right)$ and flux linkages $\left(\phi_{d}, \phi_{q}\right)$ are then computed using Park's transformation. The average torque $\left(T_{a v g}\right)$, the power factor $(P F)$ and the voltage $(V)$ are computed at 4 static positions for an accurate estimation [15]. They are expressed by (34), (35) and (36) respectively.

$$
\begin{aligned}
& T_{a v g}=\frac{3 p}{2}\left(\phi_{d} i_{q}-\phi_{q} i_{d}\right) \\
& P F=\cos \left(\tan ^{-1}\left(-\phi_{d} / \phi_{q}\right)-\tan ^{-1}\left(i_{q} / i_{d}\right)\right) \\
& V=\omega \sqrt{\phi_{d}{ }^{2}+\phi_{q}{ }^{2}}
\end{aligned}
$$

\section{FINITE ELEMENT COMPARISON}

A 2D finite element model of the studied motor is created and its results are compared with the results of the analytical model. The first motor geometry $\left(M_{l}\right)$ is reported in the APPENDIX. At first, the magnetomotive force $(\mathrm{mmf})$ is verified and the airgap flux density is shown for two pairs of current values and current angles $(\alpha)$. Then, the flux density of the stator teeth is shown and the flux density of the rotor fluxguides and exterior iron bridges are reported. Finally, the comparison of the average torque, the power factor and the voltage is conducted for $M_{1}$ and another geometry $M_{2}$ in order to verify the robustness of the analytical model.

The studied motors have $2 \mathrm{~V}$-shape flux-barriers filled with ferrite magnets and rotate at $500 \mathrm{rpm}$.

\section{A. Magnetomotive force}

In order to verify the validity of the magnetomotive force model (1) and the stator permeance function (3), the system formed by (23) and (28) was solved under linear conditions with a passive rotor disc. Thus, the terms $A t_{s}^{(\theta)}$ and $A t_{r}^{(\theta)}$ do not exist. Fig.9 shows the airgap flux density for a current value of $43 \mathrm{~A}(\mathrm{rms})$ and a current angle of $0^{\circ}$.

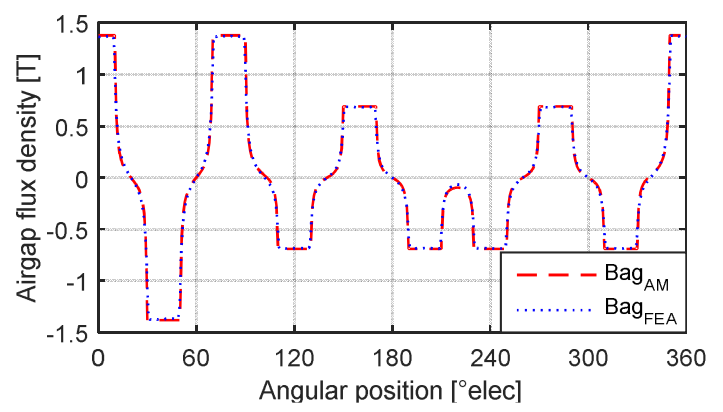

Fig.9 Airgap flux density under linear conditions and passive rotor iron disc

In this particular configuration, the airgap flux density is the image of the $m m f$ since no Ampere-turns are consumed in the motor's iron parts. The analytical model (AM) reproduces almost the exact shape of the Finite Element Analysis (FEA) result. This validates the $m m f$ and the stator saliency models for the non-overlapping concentrated tooth winding.

\section{B. Airgap flux density}

The airgap flux density of the motor $M_{1}$ is obtained by resolving the equation system (23) to (28). A comparison between the analytical model and the finite element model is made. The airgap flux density is given for two current values,
28A (Fig.10) and 43A (Fig.11) with a current angle $\alpha$ of $10^{\circ}$ elec. The analytical model gives satisfactory results and is accurate for both current values at two saturation levels of the ferromagnetic material (lower saturation at 28A and higher saturation at $43 \mathrm{~A})$.

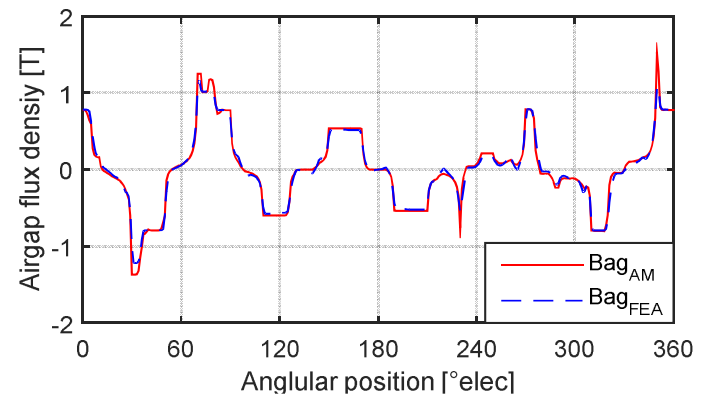

Fig.10 Comparison of the airgap flux density between the AM and the FEA (Irms $\left.=28 \mathrm{~A}, \alpha=10^{\circ} \mathrm{elec}\right)$

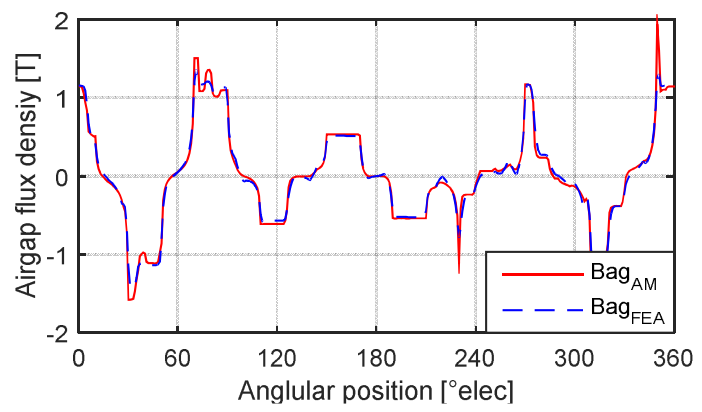

Fig.11 Comparison of the airgap flux density between the AM and the FEA (Irms $=43 \mathrm{~A}, \alpha=10^{\circ}$ elec)

\section{Flux density of the stator teeth}

The developed model of the stator teeth that takes into consideration the airgap flux density and the slot tangential leakage flux (section II-C) is computed and compared to the results of the FEA.
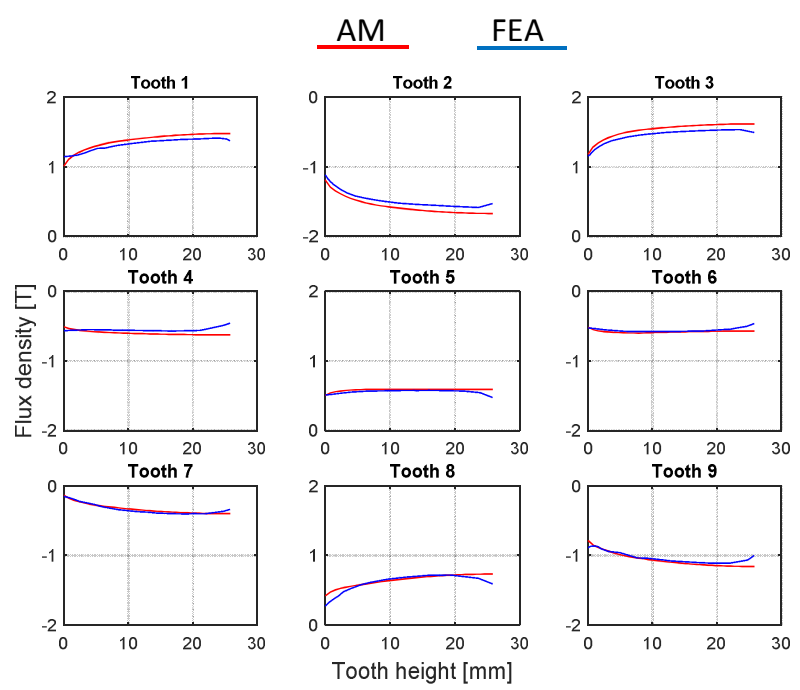

Fig.12 Comparison of the stator teeth flux density between the AM and the FEA (Irms $\left.=43 \mathrm{~A}, \alpha=10^{\circ} \mathrm{elec}\right)$

The comparison is carried out for a current of $43 \mathrm{~A}$ and a current angle of $10^{\circ}$ elec. Since only half of the motor is modeled, the number of teeth is 9. Fig.12 shows the flux density of the 9 teeth along the tooth height. The analytical model shows a good concordance with the finite element results. 


\section{Flux density of the exterior iron bridge}

Each rotor barrier has two exterior iron bridges. Their flux densities are obtained by the system of equations (32). For a current value of $43 \mathrm{~A}(\mathrm{rms})$ and a current angle of $10^{\circ} \mathrm{elec}$, the comparison of the exterior iron bridges flux density of motor $M_{l}$ between the AM and the FEA is given in Fig.13.

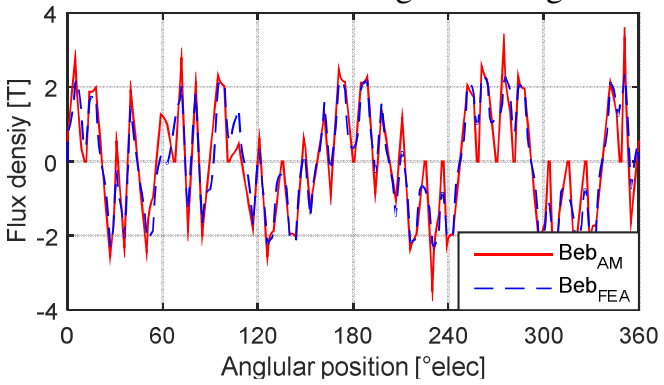

Fig.13 Comparison of the exterior iron bridges flux densities between the AM and the FEA (Irms $\left.=43 \mathrm{~A}, \alpha=10^{\circ} \mathrm{elec}\right)$

Fig.13 shows a good agreement between the AM and the FEA results. The flux density of the iron bridges can reach high saturation levels and causes the peaks observed in the AM. Despite these local peaks, the airgap flux density given in Fig.11, reflects the saturation of the motor and shows very good results when compared to the FEA.

\section{E. Flux density of the rotor}

The motor $M_{l}$ has 2 flux barriers therefore it has 2 fluxguides per pole. Fig.14 shows the flux density of the fluxguides for the first pole. It was computed along the mean flux path of the flux-guide, with a current of $43 \mathrm{~A}(\mathrm{rms})$ and a current angle of $10^{\circ} \mathrm{elec}$. The $\mathrm{x}$-axis represents the length of the flux-guide.
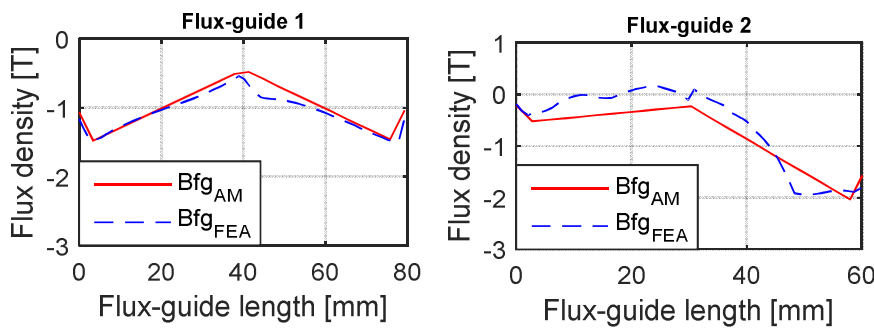

Fig.14 Comparison of the flux density of the rotor flux-guides for the $1^{\text {st }}$ pole between the AM and the FEA (Irms=43A, $\alpha=10^{\circ} \mathrm{elec}$ )

The analytical model shows good results when compared to the finite element model. The local variations of the flux density along the flux-guide shown in the FEA are close to the linear approximation of the analytical model.

\section{F. Average torque}

The average torque is computed for the motor $M_{1}$ at two current levels: $28 \mathrm{~A}$ and $43 \mathrm{~A}$. Another motor geometry is added to the comparison. The motor $M_{2}$ has the same exterior dimensions as $M_{l}$ but differs in its rotor parameters (Fig.1). The barriers parameters of both motors are given in per unit and reported in the APPENDIX. $T_{\text {avg }}$ of $M_{2}$ is also computed for a current of $28 \mathrm{~A}$ and $43 \mathrm{~A}$ (rms). Fig.15 shows the comparison of the AM and the FEA for the two motor structures. It can be seen that the curves are very close at all current levels for the two structures. The discrepancy between the two models at the maximum average torque is given in
TABLE I and is around $2 \%$ (for the two current values) which confirms the accuracy of the analytical model.
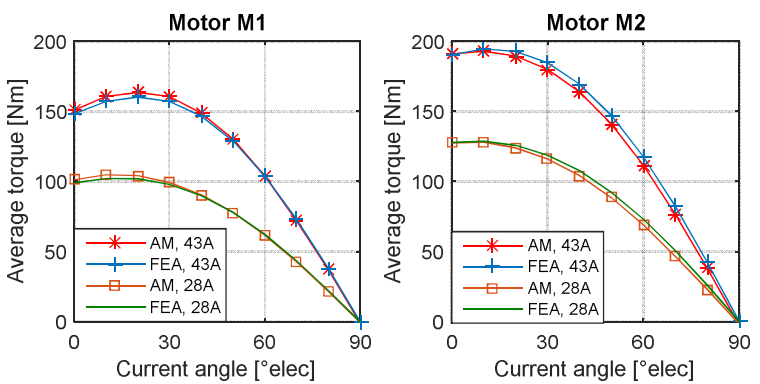

Fig. 15 Comparison of the average torque between the AM and the FEA for two motor structures

TABLE I

COMPARISON BETWEEN AM AND FEA AT MAXIMUM AVERAGE TORQUE

\begin{tabular}{ccccc}
\hline & \multicolumn{3}{c}{ M1 } & \multicolumn{2}{c}{ M2 } \\
\hline Current rms (A) & 28 & 43 & 28 & 43 \\
AM: $T_{a v g}(\mathrm{Nm})$ & 104.4 & 163.4 & 128 & 192.8 \\
FEA: $T_{a v g}(\mathrm{Nm})$ & 102.1 & 160.2 & 128.6 & 194.5 \\
Discrepancy \% & 2.2 & 2 & 0.4 & 0.9 \\
\hline \hline
\end{tabular}

\section{G. Power factor}

The power factor $(P F)$ is also computed for the two motors under the same torque conditions. The analytical model curves and the finite element curves show good agreement. Fig.16 shows the $P F$ versus the current angle.
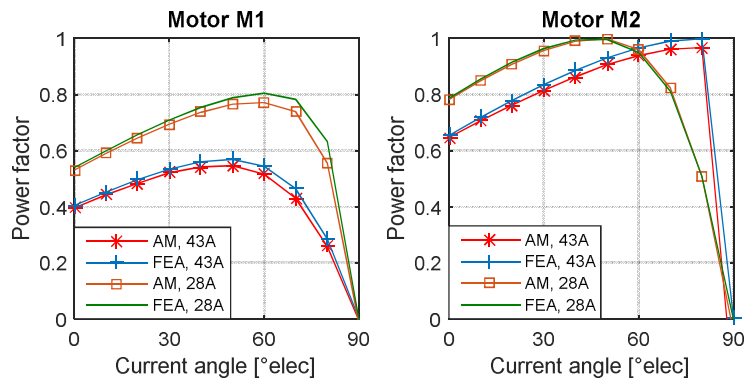

Fig.16 Comparison of the power factor between the AM and the FEA for two motor structures

At maximum average torque, the difference between the two models remains acceptable. For instance, at $43 \mathrm{~A}$ the $P F$ of $M_{l}$ is $0.48(\mathrm{AM})$ and 0.49 (FEA). For $M_{2}$ it is $0.7(\mathrm{AM})$ and 0.71 (FEA).

\section{H. Voltage}

The two motors rotate at $500 \mathrm{rpm}$. Fig. 17 shows the results for the voltage curves computed with the analytical and finite element models.
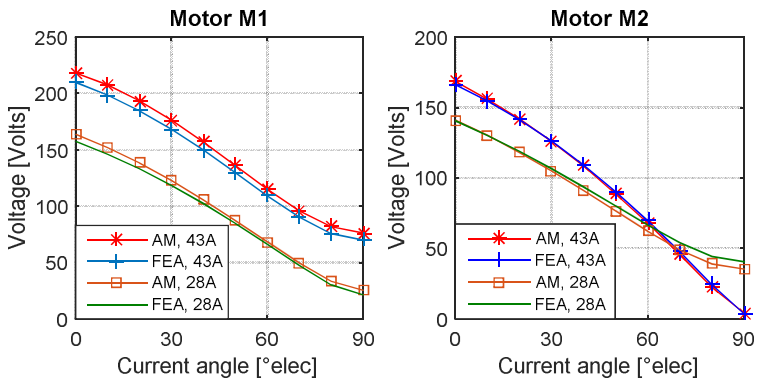

Fig. 17 Comparison of the voltage between the AM and the FEA for two motor structures 
TABLE II shows the discrepancy between the two models at the current angle that corresponds to the maximum average torque. It is less than $5 \%$ which confirms the validity of the analytical model.

TABLE II

COMPARISON OF VOLTAGE BETWEen AM AND FEA AT MAXIMUM AVERAGE TORQUE

\begin{tabular}{ccccc}
\hline \hline & \multicolumn{2}{c}{ M1 } & \multicolumn{2}{c}{ M2 } \\
\hline Current rms (A) & 28 & 43 & 28 & 43 \\
AM: Voltage (V) & 152.1 & 193.2 & 130.5 & 156 \\
FEA: Voltage (V) & 146.1 & 184.4 & 130.2 & 154.7 \\
Discrepancy \% & 4.1 & 4.7 & 0.2 & 0.8 \\
\hline \hline
\end{tabular}

\section{Computational time}

In order to obtain accurate values of the average torque, the $P F$ and the voltage, 4 static computations are needed [15]. The analytical and the finite element models are computed using Intel ${ }^{\circledR}$ Core $^{\mathrm{TM}}$ i7-4600U CPU @2.10 GHz $2.70 \mathrm{GHz}$ with 16GB RAM. The finite element model has about 20000 nodes and about 40000 elements (Fig.18). The average computational time of one calculation step is 3.1s for the AM and $17 \mathrm{~s}$ for the FEA. This makes the analytical model about 5 times faster than the finite element model.

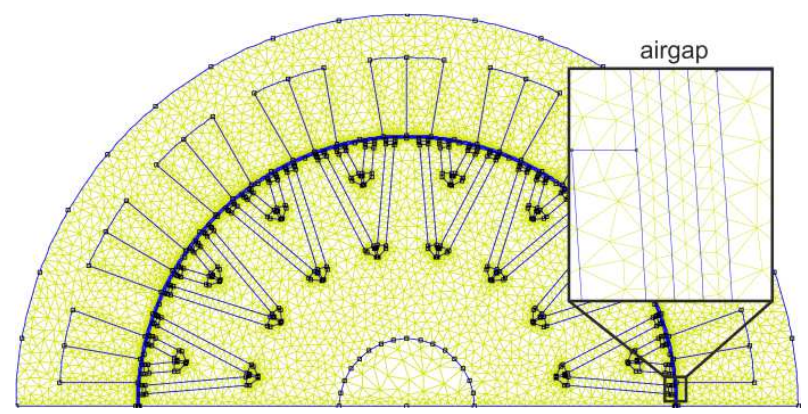

Fig.18 FEA mesh of half of the 18/16 structure

\section{EXPERIMENTAL VALIDATION}

In order to validate the analytical model, a prototype motor has been built and the experimental results were compared to the analytical ones.

\section{A. Experimental setup}

The prototype specifications are given in the APPENDIX. The stator and rotor laminations of the prototype are shown in Fig.19. The assembled motor is given in Fig.20. The experimental setup with the prototype motor, the load motor and the motor drive are shown in Fig.21.

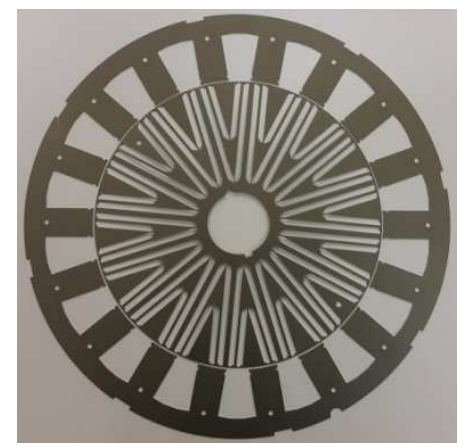

Fig.19 Stator and rotor laminations of the prototype

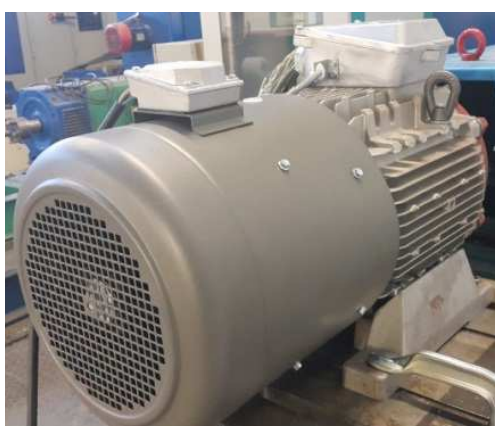

Fig.20 Assembled prototype motor

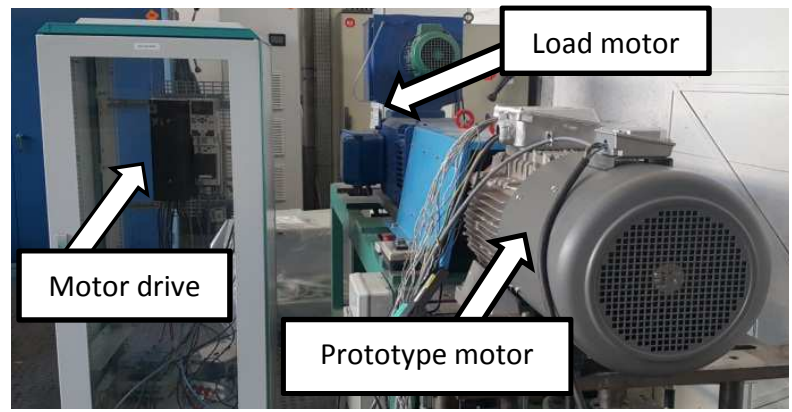

Fig.21 Experimental setup

\section{B. Experimental results}

The results of the average torque the power factor and the voltage are plotted for three current values: 12 A (Fig.22), 17 A (Fig.23) and 26 A (Fig.24).

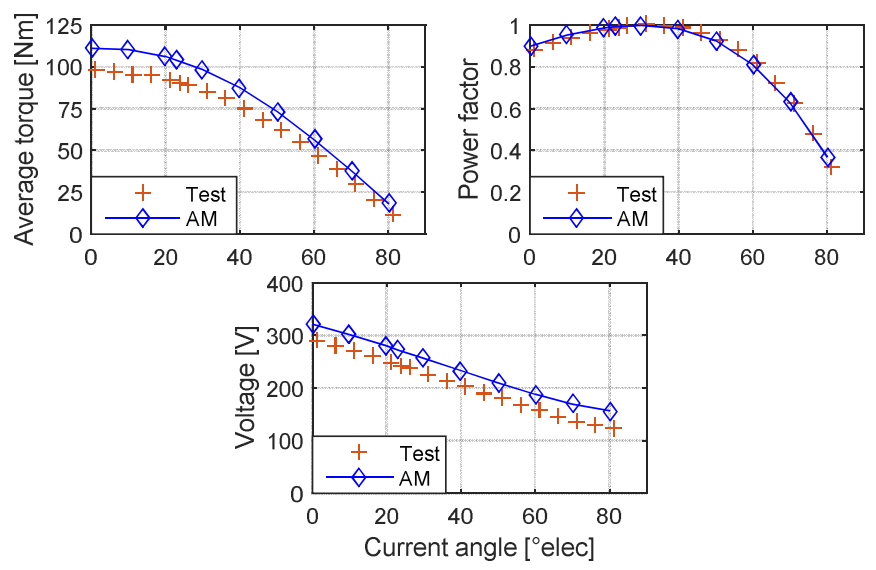

Fig.22 Validation tests $-\mathrm{I}_{\mathrm{rms}}=12 \mathrm{~A}$

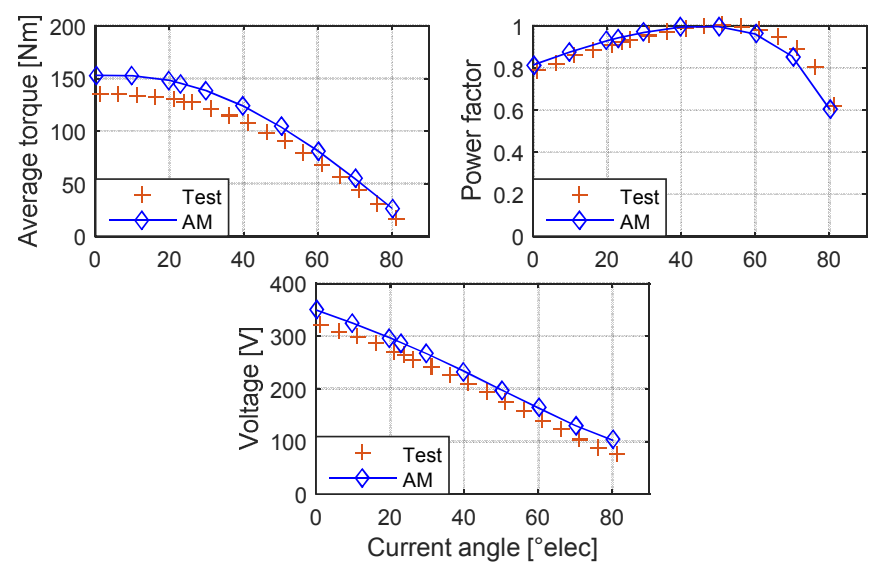

Fig.23 Validation tests $-\mathrm{I}_{\mathrm{rms}}=17 \mathrm{~A}$ 


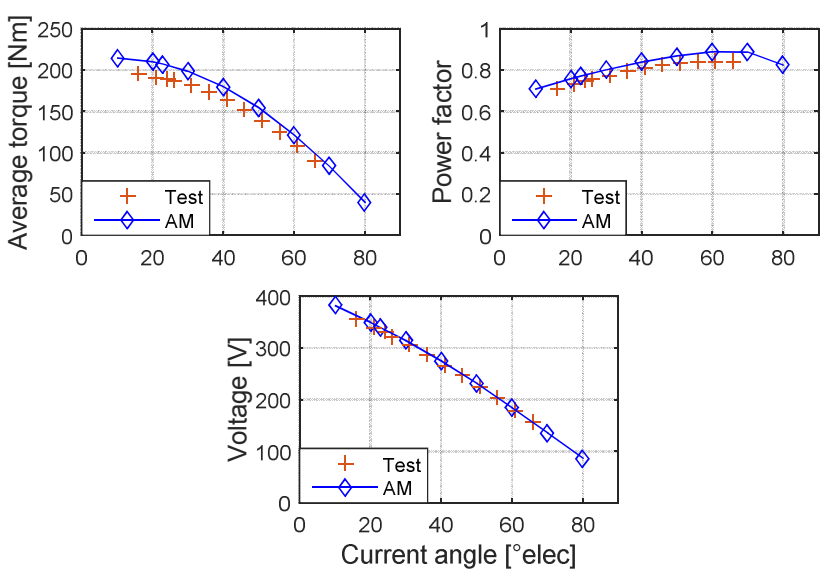

Fig. 24 Validation tests $-\mathrm{I}_{\mathrm{rms}}=26 \mathrm{~A}$

The discrepancy at the maximum average torque between the tests and the analytical results is $12.24 \%$ at $12 \mathrm{~A}, 11.76 \%$ at $17 \mathrm{~A}$ and $7.7 \%$ at $26 \mathrm{~A}$. Similar results can be found for the voltage for which the discrepancy at low current angle is $10.7 \%$ at $12 \mathrm{~A}, 8.76 \%$ at $17 \mathrm{~A}$ and $3.3 \%$ at $26 \mathrm{~A}$. This difference between the prototype and the analytical model suggests a higher saturation levels in the steel sheet that can be caused by the manufacturing process especially when cutting the barriers.

The results of the power factor computed by the analytical model match those obtained during the tests. The discrepancy is below $3 \%$. This validates the calculation of the tangential leakage flux which directly affects the power factor by the mean of the slot leakage inductance.

The non-linear analytical model has been experimentally validated. It is able to deliver accurate results which make it suitable for motor design. Thus, it can be used in a multiphysics design and optimization procedure.

\section{CONCLUSION}

This paper presented a detailed analytical model for a saturated multi-V-shape IPM with non-overlapping concentrated winding. The proposed model took into consideration the evolution of the flux density along the height of the stator teeth with the tangential slot leakage flux. The saturation in the rotor flux-guide is modeled and the local saturation in the area near the exterior iron bridges is included for a more accurate computation of the airgap flux density.

The analytical model was compared to a 2D finite element model. The results of the flux density in the different parts of the motor showed a very good agreement with the finite element analysis. The curves of the average torque, the power factor and the voltage for two motor structures showed also good agreement with the finite element model.

A prototype motor has been manufactured and used to experimentally validate the non-linear analytical model. The tests showed that the analytical model is capable of giving accurate results of the motor performance.

The analytical model is about 5 times faster than the finite element model and gives accurate results. Thus, in future work, it will be used for the electromagnetic calculation in a multi-physics optimization routine.
VI. APPENDIX

MOTOR SPECIFICATIONS

\begin{tabular}{cccc}
\hline \hline & $M_{l}$ & $M_{2}$ & Prototype \\
\hline Stator exterior radius (mm) & 130 & 130 & 130 \\
Axial length (mm) & 200 & 200 & 200 \\
Barriers width (pu) & 1 & 1.3 & 1.3 \\
Barriers tilt angle (pu) & 1 & 0.1 & 0.1 \\
Barriers opening angle (pu) & 1 & 1.5 & 1.5 \\
Number of turns per coil (pu) & 1 & 1 & 1.5
\end{tabular}

\section{REFERENCES}

[1] G. R. Slemon, "On the design of high performance PM motors," in , Conference Record of the 1992 IEEE Industry Applications Society Annual Meeting, 1992, 1992, pp. 279-285 vol.1.

[2] J. Cros and P. Viarouge, "Synthesis of high performance PM motors with concentrated windings," in Electric Machines and Drives, 1999. International Conference IEMD '99, 1999, pp. 725-727.

[3] Y. J. Zhou and Z. Q. Zhu, "Torque Density and Magnet Usage Efficiency Enhancement of Sandwiched Switched Flux Permanent Magnet Machines Using V-Shaped Magnets," IEEE Transactions on Magnetics, vol. 49, no. 7, pp. 3834-3837, Jul. 2013.

[4] S.-I. Kim, S. Park, T. Park, J. Cho, W. Kim, and S. Lim, "Investigation and Experimental Verification of a Novel Spoke-Type Ferrite-Magnet Motor for Electric-Vehicle Traction Drive Applications," IEEE Transactions on Industrial Electronics, vol. 61, no. 10, pp. 5763-5770, Oct. 2014.

[5] A. Pina and L. Xu, "Modeling of Synchronous Reluctance Motors Aidedby Permanent Magnets with Asymmetric RotorPoles," in IEEE International Electric Machines and Drives Conference (IEMDC), 2015, pp. 412-418.

[6] N. Bianchi, E. Fornasiero, M. Ferrari, and M. Castiello, "Experimental Comparison of PM-Assisted Synchronous Reluctance Motors," IEEE Transactions on Industry Applications, vol. 52, no. 1, pp. 163-171, Jan. 2016.

[7] L. Di Leonardo, F. Parasiliti, M. Tursini, and M. Villani, "Transient analysis of PM synchronous motor drives by finite element model cosimulation," in IECON 2013 - 39th Annual Conference of the IEEE Industrial Electronics Society, 2013, pp. 6834-6840.

[8] M. Hage Hassan, G. Krebs, and C. Marchand, "A simplified time stepping nonlinear mesh based reluctance network for machine design," in Electric Machines Drives Conference (IEMDC), 2013 IEEE International, 2013, pp. 879-884.

[9] M. Rottach, C. Gerada, T. Hamiti, and P. W. Wheeler, "A computationally efficient design procedure for actuator motors using magnetic reluctance-and thermal resistance network models," in 2012 XXth International Conference on Electrical Machines (ICEM), 2012, pp. 2526-2532.

[10] H. Tiegna, Y. Amara, and G. Barakat, "Overview of analytical models of permanent magnet electrical machines for analysis and design purposes," Mathematics and Computers in Simulation, vol. 90, pp. 162-177, Apr. 2013.

[11] Prieto, D., Ph. Dessante, J.-C. Vannier, X. Jannot, and J. Saint-Michel, "Analytical model for a saturated Permanent Magnet Assisted Synchronous Reluctance Motor," 2014 International Conference on Electrical Machines (ICEM), 2014, pp. 72-78.

[12] P. Akiki, M. H. Hassan, J. C. Vannier, M. Bensetti, B. Dagusé, D. Prieto, and M. McClelland, "Non-linear analytical model for a multiv-shape IPM with concentrated winding," in 2016 XXII International Conference on Electrical Machines (ICEM), 2016, pp. 479-485.

[13] G. Dajaku and D. Gerling, "Stator Slotting Effect on the Magnetic Field Distribution of Salient Pole Synchronous Permanent-Magnet Machines," IEEE Transactions on Magnetics, vol. 46, no. 9, pp. 3676-3683, Sep. 2010.

[14] B. Gaussens, E. Hoang, O. de la Barriere, J. Saint-Michel, M. Lecrivain, and M. Gabsi, "Analytical Approach for Air-Gap Modeling of Field-Excited Flux-Switching Machine: No-Load Operation," IEEE Transactions on Magnetics, vol. 48, no. 9, pp. 2505-2517, Sep. 2012.

[15] N. Bianchi and L. Alberti, "MMF Harmonics Effect on the Embedded FE Analytical Computation of PM Motors," IEEE Transactions on Industry Applications, vol. 46, no. 2, pp. 812-820, Mar. 2010. 


\section{BIOGRAPHIES}
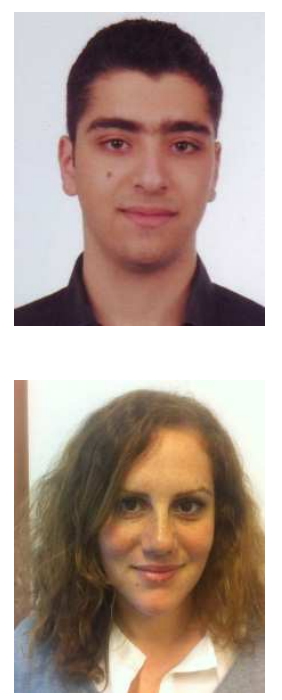

Paul Akiki received his Engineering degree and Master's degree from Ecole Supérieure d'Electricité (Supélec), France, in 2014.

$\mathrm{He}$ is currently working towards the Ph.D degree in Electrical Engineering with the Group of electrical engineering - Paris (GeePs) at CentraleSupelec, France. His current research interests include design and optimization of permanent magnet machines.

Maya Hage Hassan received her B.S. degree in mechanical engineering from the LU-Faculty of engineering, Lebanon, and her M.S. degree from the Ecole Centrale de Nantes, France, and a Ph.D. degree in electrical engineering from University Paris-Sud in 2014.

She is now an Assistant Professor at CentraleSupélec and with the Group of electrical engineering - Paris, CNRS UMR 8507. Her current research interests include optimization and design of electric machines and drives.

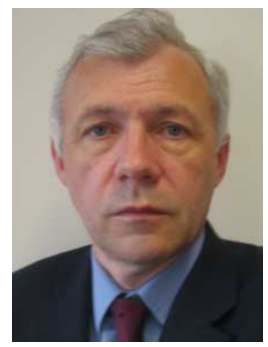

Jean-Claude Vannier received the degree in electrical engineering from Ecole Supérieure d'Electricité (SUPELEC), France, in1978, and the HDR (Accreditation to Supervise Research)degree from the Université of Paris-Sud, France, in 2006.

$\mathrm{He}$ is a Professor and head of "Department of Energy and Power Systems" at CentraleSupelec, France. His primary research interest is in energy conversion systems (motors, actuators, generators) and concerns the modeling, the design, and the optimization of this equipment.
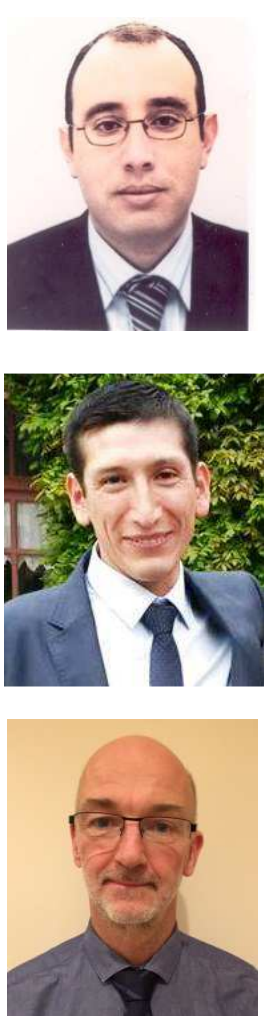

Mohamed Bensetti received his Master's degree (DEA) in 2001 and his Ph.D. in Electrical Engineering in 2004 from the University of ParisSud, France.

$\mathrm{He}$ is now an Associate Professor at CentraleSupelec and a researcher with GeePs (Group of electrical engineering -Paris). His current research interests are Electromagnetic modeling, ElectroMagnetic Compatibility (EMC) and Power Electronics, including modelling, simulation and instrumentation.

Dany Prieto received the M.S. degree in Electrical Engineering from the University of Nantes, France, in 2011 and the Ph.D. degree from CentraleSupelec in 2015.

Since 2015, he has been working with LeroySomer Motors as R\&D Electrical Engineer. His research interests include PMSM and induction motors with their power electronic supply.

Mike McClelland obtained his engineering degree from Leeds University in 1985 and $\mathrm{PhD}$ in 1994.

He has been working for Emerson ever since on the electromagnetic, mechanical and thermal design of brushless machines and is now employed as Technical Director for Leroy Somer Motors \& Drives division. He is a Fellow of the Institute of Engineering and Technology (UK). 